\begin{tabular}{|l|l|l||}
\hline \multicolumn{2}{|c|}{ PublisherInfo } \\
\hline \hline PublisherName & $:$ & BioMed Central \\
\hline \hline PublisherLocation & $:$ & London \\
\hline \hline PublisherImprintName & $:$ & BioMed Central \\
\hline \hline
\end{tabular}

\title{
Alternative therapies in rheumatology
}

\begin{tabular}{|l|l|l||}
\hline \multicolumn{2}{|c|}{ ArticleInfo } \\
\hline \hline ArticleID & $:$ & 43 \\
\hline \hline ArticleDOI & $:$ & $10.1186 /$ ar-1999-66740 \\
\hline \hline ArticleCitationID & $:$ & 66740 \\
\hline \hline ArticleSequenceNumber & $:$ & 39 \\
\hline \hline ArticleCategory & $:$ & Paper Report \\
\hline \hline ArticleFirstPage & $:$ & 1 \\
\hline \hline ArticleLastPage & $:$ & 3 \\
\hline \hline & & RegistrationDate : 1999-11-1 \\
\hline ArticleHistory & $:$ & OnlineDate \\
\hline \hline ArticleCopyright & $:$ & Current Science Ltd1999-11-1 \\
\hline \hline ArticleGrants & $:$ & \\
\hline \hline ArticleContext & $:$ & 130752211 \\
\hline \hline
\end{tabular}




\section{Keywords}

Alternative medicine, complementary medicine, fibromyalgia, osteoarthritis, rheumatoid arthritis, therapeutics

\section{Context}

Previous studies have shown that a significant number of Americans with chronic medical conditions use non-traditional therapies for their disease. Patients with rheumatoid arthritis are no exception, with a very high percentage of patients using therapeutic modalities that can be defined as belonging to the realm of complementary or alternative medicine. To Examine the use of non-conventional alternative therapies among patients attending rheumatology clinics, and to identify factors correlating with such use.

\section{Significant findings}

About $50 \%$ of potentially eligible patients (232 out of 428 ) responded to the survey. The responding patients were mostly women, predominantly white, with a mean age of 55 years. The most common rheumatologic diagnosis was rheumatoid arthritis, followed by fibromylagia and osteoarthritis (with minimal overlap between these diagnostic categories). More than $60 \%$ of the patients that responded to the survey used at least one type of alternative modality for their disease. The most common reasons cited for using alternative modalities were to deal with pain, and to help with their disease. Less than half of the patients reported the use of alternative medicine to their physicians, usually because the physician did not inquire about such use. Multivariate analysis showed that factors associated with alternative medicine use included a diagnosis of osteoarthritis, severe pain, and a college degree.

\section{Comments}

The use of complementary and alternative medicine modalities was frequent in patients attending rheumatology practices in this survey. Potential limitations of this study include a relatively low response rate and studying patients limited to a single geographical area. Nevertheless, these results confirm what is known from other studies, and indicate that alternative medicine approaches are in 
widespread use among patients with rheumatologic diagnoses. One theoretical attraction of alternative medicine modalities is the widespread assumption that they are free from side effects. However, there are an increasing number of reports in the literature concerning serious adverse effects and even mortality from supposedly benign non-traditional therapies. Rheumatologists need to be aware of the use of complementary and alternative medicine modalities by their patients, and to counsel them appropriately. Properly conducted studies into the mechanism of action and the efficacy of nontraditional therapeutic approaches for rheumatologic conditions are very much needed.

\section{Methods}

Outpatients attending six different rheumatology clinics in Indiana, (in university and private settings) over 2 weeks in 1997, were potentially eligible for the study. Exclusion criteria were patients on their first clinic visit, age of less than 18 years, or altered mental status. Patients were informed of the study during their clinic visit, and asked to agree to a subsequent telephone survey.

\section{References}

1. Rao JK, Mihaliak K, Kroenke K, Bradley J, Tierney WM, Weinberger M: Use of complementary therapies for arthritis among patients of rheumatologists. Ann Intern Med. 1999, 131: 409-416.

This PDF file was created after publication. 